\title{
Effectiveness of environmental management institutions in sustainable water resources management in the upper Hanjiang River basin
}

\author{
Ru Qian ${ }^{1}$, Dong $\mathrm{Hao}^{2,3,4,5^{*}}$, Li Zongwu ${ }^{1}$, Duan Mengge ${ }^{1}$ \\ ${ }^{1}$ Hanzhong Branch of Shaanxi Land Engineering Construction Group Co. , Ltd. ,HanZhong 723000,Shaanxi; \\ ${ }^{2}$ Shananxi Land Engineering Construction Group Co.,Ltd.,Xi' an 710075,China; \\ ${ }^{3}$ Institute of Land Engineering and Technology,Shaanxi Land Engineering Construction Group Co.,Ltd.,Xi'an 710075,China; \\ ${ }^{4}$ Key Laboratory of Degraded and Unused Land Consolidation Engineering,the Ministry of Natural Resources,Xi' an 710075,China; \\ ${ }^{5}$ Shaanxi Land Consolidation Engineering Technology Research Center,Xi'an 710075, China )
}

\begin{abstract}
The Han River valley plays an important strategic role in the water resources allocation system in China. A parallel hybrid approach was used in the study, using both qualitative and quantitative data collection and analysis techniques. Twenty self-administered questionnaires were sent to the heads of the environment bureaus of 17 districts (counties) and 3 cadres of the natural resources bureaus. Three in-depth interviews were conducted with the head of the water authority in the basin. Runoff, water quality and sediment load data were collected over a 17-year period and trends were analyzed using Mann-Kendall and regression analysis statistics to predict future water levels. The results show that the positive linear correlation between runoff $\mathrm{R}$ and sediment load is $\mathrm{R} 2=0.1718$, while the negative linear correlation between sediment load and $\mathrm{pH}$ value is $\mathrm{R} 2=0.0329$. According to the Mann-Kendall analysis $(\mathrm{p}>0.05)$, no statistically significant trend was found in the data. The study concluded that there was a lack of effective regular interaction and cooperation between water and environmental management at the basin level. Effective Coordination of environmental management remains key to achieving sustainable water resources management in the Han River River Basin.
\end{abstract}

\section{Introduction}

The Shaanxi Provincial Bureau of Ecological Environment and the Bureau of Natural Resources are the leading departments of environment and natural resources in the upper reaches of the Hanjiang River basin. Their activities are guided by the Environmental Protection Law of the people's Republic of China, which is a programmatic law on environmental management in China. China uses the legal system (regulations, systems, laws) to manage the environment and provide incentives to relevant companies and institutions to encourage self-regulatory ${ }^{[1-2]}$. The Hanjiang River Basin in Shaanxi Province has three main environmental management departments: the Ecological Environment Bureau, the Natural Resources Bureau and the Water Conservancy Bureau (some areas have not been incorporated into the Natural Resources Bureau). At the same time, the three departments chaired the on all water resources management in the basin ${ }^{[3]}$.

Integrated water resources management is defined as " a process that promotes the coordinated development and management of water, land and related resources with the aim of maximizing the economic and social benefits of production in an equitable manner without compromising the sustainability of important ecosystems

*DongHao's e-mail: donghao19@stu.xjtu.edu.cn
"[4]. Integrated water resources management is based on four principles developed at the International Conference on Water and the Environment, held in Dublin in 1992 [5].

\section{Materials and methods}

\subsection{Research design}

This study uses parallel mixing method design as research, quantitative and qualitative data. Parallel mixing method can triangulate the data, methods and theories of the research, so that the research results tend to be consistent, thus improving the credibility of the research. this approach can clarify and interpret quantitative data through narrative and dialogue. Because qualitative and quantitative design are complementary under the mixed method research design, the research problems and results are better understood. Figure 1 below illustrates the model followed by the study.

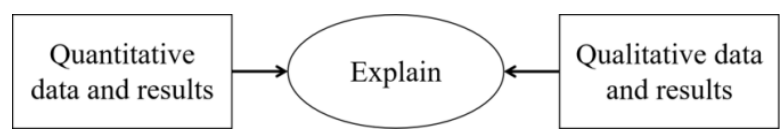

Fig.1 Concurrent mixed methods research model 


\subsection{Study area}

The study area is located in the upper part of the upper Hanjiang River basin in Hanzhong City, Shaanxi Province, and most of it is located in Chenggu County. The county is one of ten counties in Hanzhong, located in the center of Hanzhong Basin in southern Shaanxi, with a total area of 2265 square kilometers. Chenggu terrain is high in the north and low in the south. It belongs to the subtropical humid monsoon climate, warm and humid, with four distinct seasons. The annual average temperature is $14.3^{\circ} \mathrm{C}$ and the annual rainfall is 843.9 $\mathrm{mm}$.

\section{Data acquisition}

Combined with the laws and regulations on water and environment and the relevant questionnaires and data collected over the years, according to the $\mathrm{pH}$ value of the upper reaches of the Hanjiang River, the practical ideas of upstream land use provided by river sediment load and runoff data. these data are analyzed using a Mann-Kendall test, a rank-based nonparametric statistical test widely used in trend analysis. and then use regression analysis to establish the relationship between sediment load and runoff and sediment load and $\mathrm{pH}$. then, the results of the analysis data are displayed by using graphs, graphs and equations.

Calculation formulas for Mann-Kendall test statistics are as follows:

$$
S=\sum_{i=1}^{n-1} \sum_{j=i+1}^{n} \operatorname{sgn}\left(X_{j}-X_{i}\right)(1)
$$

where are Mann-Kendall statistics, and represent the annual data values for the $i$ and $j$ years $(i>j)$, and are records of sequence length. The positive value represents the upward trend, the negative value represents the downward trend, and the is the characteristic of the function.

A relational model between runoff and sediment load is established by using the following equations.

$$
R_{1}=\alpha_{1} \gamma_{j}+\alpha_{2} \gamma_{j+1}+\ldots \ldots+\alpha_{n} \gamma_{j+n+1}+e(2)
$$

where represents annual runoff (m3) or $\mathrm{pH}$, represents annual sediment load (m3)

\section{Results and discussion}

F22 hydrological monitoring station recorded 131720 tons of load in the upper reaches of the Hanjiang River during the hydrological season in June 2005(Fig .2). The following year recorded a minimum level of 1352 tons in July 2006. Usually, Four seasons of sediment loading range from 10,000 tons to 40,000 tons, so there are three outliers 118681,131720,1352. The average river sediment at the station is 45366 tons, The standard deviation is 50576 tons. $\mathrm{m} 3,280000$ runoff $85 \%$ of the annual flood volume m3 330000, So June 2005 Sediment levels may be the result of flash floods. Mann-Kendall analysis ( $p>0.05$ ) showed that no statistically significant trend was detected in the data. Chen Hao and Dong Qian (2019) carried out a related study to evaluate the of gravel extraction and water and sediment transport in Shuifeng reach [16]. The results show that natural and human factors affect the movement of sediment and sediment in river course, and its level varies with time and space.

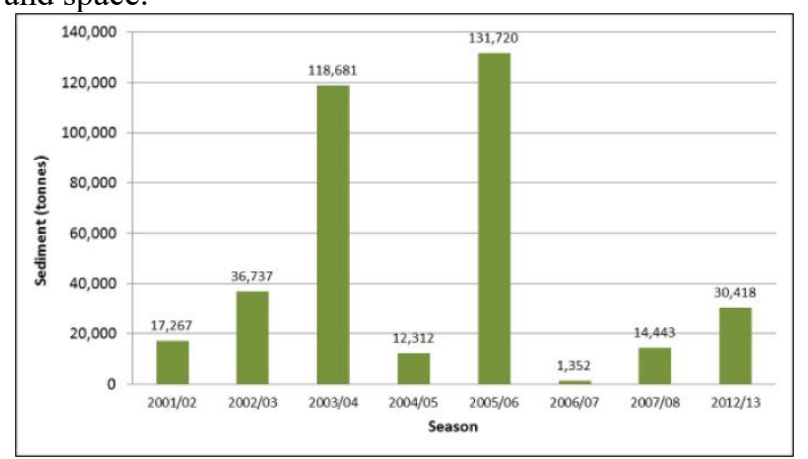

Fig.2 Annual sediment load at F22

\subsection{Relationship between sediment load and runoff}

Fig .3 shows the regression lines and equations of the relationship between river runoff and sediment load in the upper reaches ofrometeorological station in the upper reaches of the Hanjiang River. the figure shows a positive linear relationship between the runoff and the amount of sediment sediment contained in the flowing water. However, the equation can not predict very accurate results $\mathrm{R} 2=$ determining the coefficient of 0.1718. In April 2003 and June 2005, two extremely high sediment load values greatly affected the regression equation. The figure shows that the increase of river runoff also leads to the corresponding increase of sediment in water.

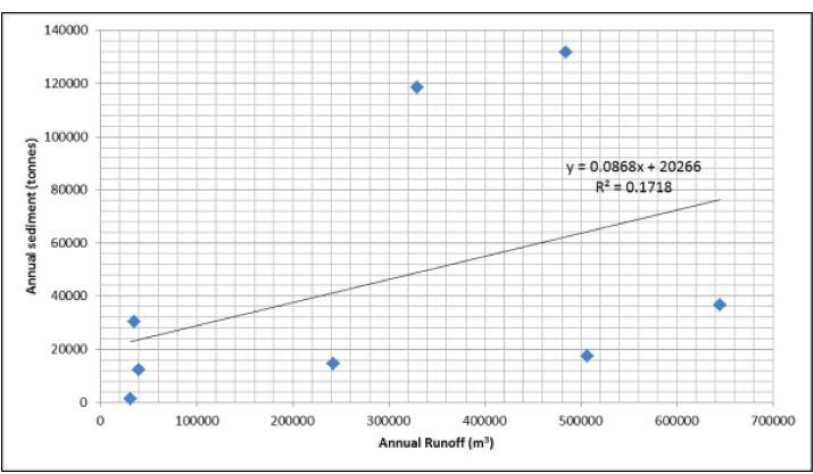

Fig.3 Relationship between annual runoff and river sediment load

\section{Conclusion}

Mann-Kendall analysis ( $>0.05)$ showed that no statistically significant trend was detected in the data. A regression analysis of quantitative data shows that the increase of river runoff often leads to the increase of river sediment load and the decrease of water $\mathrm{pH}$ value level. Therefore, the lack of sustainable environmental management practices may lead to further deterioration in the quality and quantity of water resources in the upper reaches of the Han River basin. The head and head 
of the water and environmental management department in the upper reaches of the Han River said that the main environmental challenges include streams, siltation, water pollution, deforestation and water shortage. All respondents responded Active activities are being carried out to address the environmental challenges of the basin. However, many of the contacts between the Bureau of Ecology and Environment, the Bureau of Natural Resources and the Bureau of Water Management appear to occur at higher rather than lower levels.

\section{Reference}

1. Xie,M.,2006.Integrate Water Resources Management(IWRM) : Introduction to Principles and Practices. World Bank Institute.
2. Hesse-Biber and Leavy, 2011. The Practice of Qualitative Research, second ed. Sage, Los Angeles.

3. O’Leary, Z., 2010. The Essential Guide to Doing Your Research Project. Sage, London.

4. Black, R.T., 2009. Doing Quantitative Research in the Social Sciences: an Integrated Approach to Research Design, Measurement and Statistics. Sage, London.

5. Gumindoga, W., Shekede, M.D., Rientjies, H.T.M., Rwasoka, D.T., 2012. Incorporation of land use and land cover into hydrological dynamics of the mukuvisi and marimba river catchments.Hydrology: thirteenth waternet/WARFSA/GWP-SA.In: International Symposium on Integrated Water Resources Management(Johannesburg). 